\title{
EMERGY-BASED URBAN ECOSYSTEM HEALTH EVALUATION FOR A TYPICAL RESOURCE-BASED CITY: A CASE STUDY OF TAIYUAN, CHINA
}

\author{
GuO, X. J. ${ }^{1,2}-$ DonG, S. C. ${ }^{2,3}-$ WANG, G. K. ${ }^{4}-$ LU, C. P. ${ }^{5 *}$ \\ ${ }^{I}$ College of Geographical Science, Shanxi Normal University, Linfen 030024, China \\ ${ }^{2}$ Institute of Geographic Sciences and Natural Resources Research, Chinese Academy of \\ Sciences, Beijing 100101, China \\ ${ }^{3}$ University of Chinese Academy of Sciences, Beijing 100101, China \\ ${ }^{4}$ College of Tourism, Xinyang Normal University, Xinyang 464000, China \\ ${ }^{5}$ Institute of County Economy Developments \& Rural Revitalization Strategy, Lanzhou \\ University, Lanzhou 730000, China \\ *Corresponding author \\ e-mail:lcp@lzu.edu.cn 2575
}

(Received 28 $8^{\text {th }}$ Jun 2019; accepted 25 ${ }^{\text {th }}$ Oct 2019)

\begin{abstract}
Urban ecosystem health assessment helps ensure sustainable urban development. As the provincial capital of Shanxi in China, Taiyuan's development also affects Shanxi, an area rich in coal resources, and its urbanization is closely related to the coal energy structure, which has led to ecological deterioration. This study aims to apply emergy synthesis and information entropy to estimate the urban ecosystem health of Taiyuan during the 2001-2017 period, to provide insight into the policy implications. The results indicated that the urban ecological health of Taiyuan has ameliorated during the 17-year period, mainly due to the resilience and ecological service capacity of Taiyuan urban ecosystem improved over the past 17 years. The continuous reduction of industrial waste emissions leads to ecosystem, which have resilience improving. However, we should be cautious since there are still a lot of problems with the organizational structure. And Taiyuan government still needs to adjust the current energy structure, optimize industrial structure, and reduce the dependence on the resources.
\end{abstract}

Keywords: city ecosystem, health evaluation, emergy analysis, information entropy, coal-based city

\section{Introduction}

"For better or For Worse, For Richer or For Poorer", the words are often part of a traditional Western wedding ceremony, but they also seem to define dilemma city development may bring. Cities always play an important role in local region economic and population agglomerations, politics, social services, and human culture (Pan et al., 2019), and make human life productive and colorful. Consider our polluted environment 
and our increased greenhouse gas emissions and municipal solid wastes along with urban expansion and economic development. It is no doubt that without control, urbanization will not only affect living standard and region social economic development, but also result in the collapse of urban ecosystem itself (Liu et al., 2009a). Since the middle of the 20th century, countries all over the world have experienced tremendous changes from rural to urban areas, especially in developing countries, like China which is the largest developing country in the world (Pan et al., 2019). The urbanization of China was $17.92 \%$ in 1978 , surge to $59.58 \%$ in 2018 , at the same time, the volume of wastewater discharge has surged more than two times, the final energy consumption has surged about six times, and $\mathrm{SO}_{2}$ emission has increased almost two times, compared with the values in 1985 (Zhang et al., 2016). In view of these increasing serious environmental problems, the Chinese government has formulated many policies and regulations aimed at achieving sustainable development (Chen et al., 2018). Therefore, it makes sense to evaluate the urban ecosystem health, and offer a better understanding of energy and materials metabolism, which is essential for future decision makers at various levels to address urban ecosystem equilibrium and sustainable economic and social development.

Urban ecosystems exist in the form of open, thermodynamic and far-from equilibrium (Odum, 1979), which rely on the continual input of high quality, low-entropy energy and waste emission to the ecosystem (Liu et al., 2009b). Given that a healthy urban natural ecosystem is equally important for economic and social sustainability (Liu et al., 2009b), subsequently, increasing efforts have been made to protect ecosystem health as a new goal in the environmental management processes. Particularly, urban ecosystem, as a network of multiple interactive relationships (Xiao et al., 2019), and it is usually evaluated by building assessment model. To date, Material Flow Analysis (MFA) (Huang et al., 2006; Barles, 2009; Kovanda et al., 2009; Browne et al., 2011), Ecological Footprint (Bagliani et al., 2008; Graymore et al., 2008; Zhou and Imura, 2011), Life Cycle Assessment(Perkins et al., 2009; Zhang et al., 2010b) are widely used methods for accounting for inputs, outputs, throughputs and storages in urban area (Ricardo et al., 2013). Exergy (Xu, 1997; Gommans and Dobbelsteen, 2007), and Emergy synthesis (Zhang et al., 2011; Viglia et al., 2018) have been proposed and applied to evaluate urban ecosystem health. However, material flow analysis and ecological footprint methods cannot fairly reveal the characteristics of environmental integrity and resource utilization of socio-economic systems (Chen et al., 2018). Also, those methods can hardly accurately judge the real contribution of local ecosystem to local economic development (Chen et al., 2018). Compare to other methods, emergy promotes the environmental support for resource flows and related support for ecosystem services maintaining the economy of the region under study, rather than other aspects, such as thermodynamic and utilization efficiencies (Ricardo et al., 2013). The emergy theory put forward by Odom in the late 1980s provides a method to combine environment and social and economic flows (such as energy, material, 
information, currency, resources and labor), measured by a common unit (the solar emergy joule abbreviated to sej). Besides, taking into account the 'free of charge' of environmental work and the quality of the resources (Ricardo et al., 2013). Emergy synthesis has been widely used to assess the sustainability of countries, regions and cities (Zhang et al., 2011; Yu et al., 2016; Chen et al., 2018; Viglia et al., 2018). The remarkable advantage of emergy synthesis is that it can reveal the quantity and quality of the input flow and track the interactions among the components of the urban ecosystem (Liu et al., 2019).

China is rich in coal resources which account for $13 \%$ of the global recoverable reserves (Xu et al., 2015). Given this reason, the rapid urbanization of China is highly correlated with its coal energy structure. And Shanxi Province, the most important energy bases in China, only cover $1 / 60$ territory but its coal production accounts for over $1 / 4$ of the entire quantity in China (Guo et al., 2018). Taiyuan, as the capital city of Shanxi, its development is also a microcosm of Shanxi, that coal related industry contributed to more than half of its GDP in the past decades. It is no doubt that the key to the problem lies in the metabolic imbalance of resource-based cities and the high proportion of urban heavy industry, so it is necessary to adjust the industry. Local government try to support the tertiary industry and new environmental protection non-resource industries from the aspects of government policy, science and technology, funds, talents and so on. At the same time, the government push on the heavy industry enterprises and resource enterprises upgrade the technology, increase the added value of products, and reduce product pollution. The scientific basis of all this is to find out the existing state of urban ecosystem, the health evaluation of ecosystem and the main problems. Only in this way can the government take targeted measures. In this study, we take the typical coal-based Taiyuan City as the research target, aims to construct a framework and propose the index system for evaluating the health status of urban ecosystem based on emergy theory. Particularly, this research provides an empirical evidence for the evolution of the characteristics of urban ecosystem and ecological efficiency based on emergy synthesis of Taiyuan over the period 2001-2017.

\section{Materials and Methods}

The process of emergy analysis is based on the energy symbol language, and this research builds a framework to emergy diagram of social, economic and environmental interactions in a given urban ecosystems (Fig. 1). With a view to the dynamic simulation, emergy synthesis was propitious to assesses the input/output flows, and calculate efficiency and environmental loading (Liu et al., 2009b). The emergy system diagram of each renewable and unrenewable resource can be figured out by multiplying its energy with its transformity (Wang et al., 2019). The renewable resource emergy (R) of the urban ecosystem was obtained by taking the sum of the solar, geothermal inputs, the secondary and tertiary inputs (such as wind, rain, runoff). Besides, Non-renewable 
resource emergy $(\mathrm{N})$ is also one of the basic inputs to the urban ecosystem. At the same time, the urban ecosystem receives the input of capital, material and manpower flow, and finally through economic activities exports products and services, also produce waste $(\mathrm{W})$.

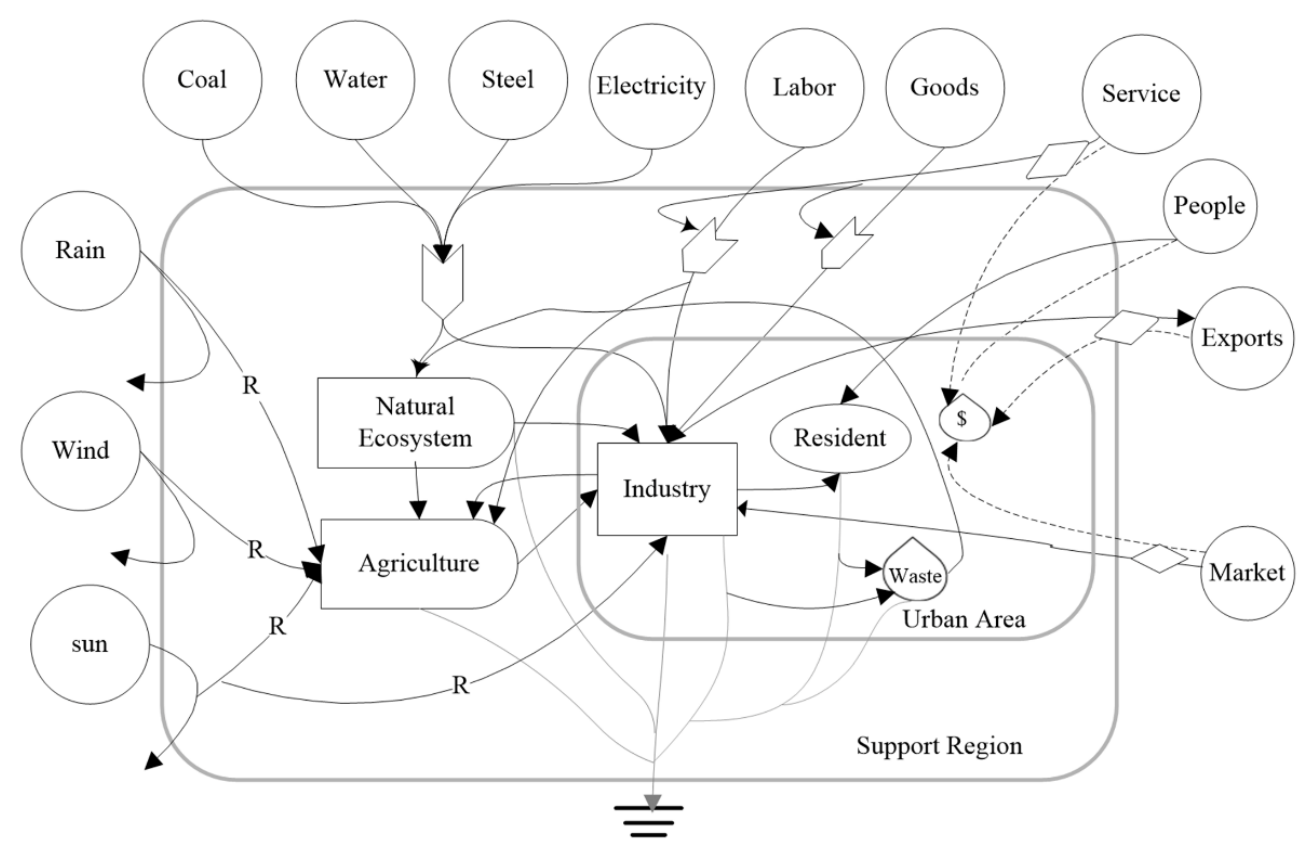

Figure 1. Emergy system diagram of Taiyuan urban ecosystems

In this paper, derived from emergy synthesis theory, the comprehensive indicator system of emergy value (Table 1) is built to synthetically analyze the material flow, energy flow, money flow and population flow, a set of index and ratios appropriate to policymaking were calculated, and make a unified quantitative analysis of urban ecosystems, finally reveals the evolution trend and characteristics of urban ecosystem.

- Emdollaratio $(E D R)=U$ / GDP. It means that how much emergy would be put into generating an average unit of money in a given year (Viglia et al., 2018). Generally, this ratio is higher in less developed regions because most of the environmental resources are used free of charge. On the contrary, this ratio is usually lower in developed countries because of rapid currency repayments and the huge import of resources.

- Emergy self-sufficiency rate $(\mathrm{ESR})=\left(\mathrm{R}+\mathrm{N}-\mathrm{Em}_{\mathrm{O}}\right) / \mathrm{U}$, this rate means that renewable and nonrenewable use of research area to the total emergy use of the research area, was used to evaluate the contribution of local ecosystem to Taiyuan urban ecosystem. The higher the value of ESR, the less reliance on imported resources and the higher economic security (Chen et al., 2018). 
- Emergy exchange rate $(\mathrm{EER})=\mathrm{Em} / \mathrm{Emo}$. This rate explains the emergy exchanged in a trade or purchase, equal to the ratio of emergy imput to emergy export) (Lei et al., 2010).

- Emergy density $(\mathrm{ED})=\mathrm{U} /$ Area, this index reflects resource available for economic utilization intensity per unit territory, equal to the ratio of total used natural resources to the total regional area (Yu et al., 2016).

Table 1. The index system of the urban ecosystem health assessment

\begin{tabular}{|c|c|c|c|}
\hline Factor & Indicator & Expression & unit \\
\hline \multirow{8}{*}{ Emergy Flow } & Renewable resource emergy & $\mathrm{R}$ & sej/yr \\
\hline & Non-renewable resource emergy & $\mathrm{N}$ & sej/yr \\
\hline & Input emergy & $\mathrm{Em}_{\mathrm{I}}$ & sej/yr \\
\hline & Output emergy & Emo & sej/yr \\
\hline & Waste emergy & $\mathrm{W}$ & sej/yr \\
\hline & Total emergy & $\mathrm{U}=\mathrm{R}+\mathrm{N}+\mathrm{Em}_{\mathrm{I}}$ & sej/yr \\
\hline & Population & - & - \\
\hline & GDP & - & $\$$ \\
\hline \multirow{4}{*}{$\begin{array}{c}\text { Vigor } \\
\left(w_{i} \text { NEYR }+w_{j} \text { ED }+w_{k} \text { REE }+w_{l}\right) \\
\text { EIR })\end{array}$} & Net emergy yield ratio (NEYR) & $(\mathrm{N}+\mathrm{R}+\mathrm{Em} \mathrm{I}) / \mathrm{Em}_{\mathrm{I}}$ & - \\
\hline & Emergy density (ED) & $\mathrm{ED}=\mathrm{U} / \mathrm{Area}$ & $\mathrm{sej} / \mathrm{m}^{2}$ \\
\hline & ratio of electricity emergy used (REE) & elec/U & - \\
\hline & emergy investment ratio (EIR) & $\mathrm{Em}_{\mathrm{I}} /(\mathrm{R}+\mathrm{N})$ & - \\
\hline \multirow{3}{*}{$\begin{array}{c}\text { organization } \\
\left(\mathrm{w}_{\mathrm{i}} \mathrm{NER}+\mathrm{w}_{\mathrm{j}} \mathrm{EPC}+\mathrm{w}_{\mathrm{k}} \mathrm{EER}\right)\end{array}$} & Non-renewable emergy ratio (NER) & $\mathrm{N} / \mathrm{U}$ & - \\
\hline & Emergy per capita (EPC) & U/Population & sej/person \\
\hline & Emergy exchange rate (EER) & EmI / Emo & - \\
\hline \multirow{2}{*}{$\begin{array}{c}\text { Resilience } \\
\left(w_{i} \text { ELR + } w_{j} \text { WPR }\right)\end{array}$} & Environmental load rate (ELR) & $(\mathrm{U}-\mathrm{R}) / \mathrm{R}$ & - \\
\hline & Waste produce ratio (WPR) & $\mathrm{W} / \mathrm{U}$ & - \\
\hline \multirow{3}{*}{$\begin{array}{c}\text { Ecosystem service } \\
\left(\mathrm{w}_{\mathrm{i}} \mathrm{EDR}+\mathrm{w}_{\mathrm{j}} \mathrm{ESR}+\mathrm{w}_{\mathrm{k}} \mathrm{ESI}\right)\end{array}$} & emdollaratio (EDR) & U/GDP & sej/US \$ \\
\hline & Emergy self-sufficiency rate (ESR) & $(\mathrm{N}+\mathrm{R}-\mathrm{Emo}) / \mathrm{U}$ & - \\
\hline & Emergy Sustainability Index (ESI) & NEYR/ELR & - \\
\hline
\end{tabular}

- Emergy investment ratio $(\mathrm{EIR})=\mathrm{Em}_{\mathrm{I}} /(\mathrm{R}+\mathrm{N})$. It mainly measures the energy input required from the local resources of the development unit. In order to make the production process more economical, the rate of stakeholder should be similar to the other competitors. The size of the index is often constrained by political or socio-economic factors.

- Net emergy yield ratio $(\mathrm{NEYR})=(\mathrm{R}+\mathrm{N}+\mathrm{Em} \mathrm{I}) / \mathrm{Em}$. This index represents the satisfaction of economic processes in providing basic emergy for economic activity. By comparing the net emergy yield ratio, we can better understand whether a resource is competitive or not, and the economic benefit large or small. If NYER is small, it shows 
that the competitiveness of the resources is weak and the return benefit is lower. On the contrary, the competitiveness is stronger and the development benefit is higher.

- Environmental load rate $(\mathrm{ELR})=(\mathrm{U}-\mathrm{R}) / \mathrm{R}$. This index is equal to the ratio between the purchased and non-updated local energy values and the free environmental energy values (renewable resource energy values). Odum claims that this ratio is similar to the load on the circuit. A large ratio value indicates that the higher intensity of energy utilization in the social economic system, which leads to the greater pressure on the urban environmental system (Dong et al., 2011). ELR is a warning to the social economic system, once the urban social economic system is always in a high ELR, will result in irreversible degradation or loss of ecological service function. From the perspective of emergy analysis, a large amount of energy derived from outside world and over-exploitation of local non-renewable resources are the mainspring of the environmental deterioration.

- Emergy Sustainability Index (ESI) = NEYR / ELR, this index was often used to evaluate the sustainable development status of local ecosystem combining both environmental impaction and social economic yield (Liu et al., 2009a). It is obvious that if the economic system of a country or region has a high energy output rate and with a relatively low environmental load rate, the local economic system is sustainable and, conversely, unsustainable. However, it is not absolutely that a higher ESI value represents a higher sustainability. In general, the ESI value between 1 and 10 indicates the vitality and development potential of economic system, and ESI > 10 is a symbol of economic underdevelopment. Viglia et al. (2018) believes that when ESI $<1$, it is a consumer economic system.

- ratio of electricity emergy used $(\mathrm{REE})=$ elec / $\mathrm{U}$, this index was often used to evaluate the vigor of the urban ecosystem, because electricity can reflect the extent of development in the area and further measure the efficiency, competitiveness and viability of the system.

- Non-renewable emergy ratio $(\mathrm{NER})=\mathrm{N} / \mathrm{U}$, this indicator reflects the structure of energy use, especially the proportion of non-renewable resources used. The larger the specific value, the greater the system relies on fossil energy, and the unsustainable risk is high.

- Emergy per capita $($ EPC $)=\mathrm{U} /$ Population, usually reflected economic influence to environment and the people life level.

- Waste produce ratio $(\mathrm{WPR})=\mathrm{W} / \mathrm{U}$, this indicator implys the impact of economic development model on the environment.

Based on Vigor-Organization-Resilience model (VOR) proposed by Costanza, was a widely used Ecosystem health Assessment model, and then complementing an important ecosystem service index, therefore the improved VOR model termed the VORS model (Yan et al., 2016). Based on the systematic understanding of urban ecosystem healthy and its feature (Liu et al., 2009a; Jiang et al., 2009; Yan et al., 2016) and combining the emergy based indicators (Huang et al., 2007; Su et al., 2009, 2010), 
thereby the framework of emergy-based urban ecosystem health index is built including vigor (V), organization (O), Resilience (R) and ecosystem service (S) four factors (Su et al., 2009), and reveal the biophysical foundation of environmental impaction to the urban ecosystem health (Table 1). Finally, the index system is represented by 14 emergy based indicators expressing different aspects of the urban ecosystem health.

Vigor manifests the ecosystem activities, including material and energy metabolism, as well as primary productivity (Yan et al., 2016). Efficiency and flux of the urban ecosystem states, reflect the vigor of the urban ecosystem (Liu et al., 2009a). This research selected the Net Emergy Yield Raito (NEYR) index, because it directly reflected the satisfaction of economic processes and provided a basic emergy for economic activities (Yan et al., 2016). The ratio of electricity emergy used (REE) was chosen, because electricity can reflect the extent of development in the area and further measure the efficiency, competitiveness and viability of the system (Huang, 2004; Su et al., 2010). The emergy investment ratio reflected the energy input required from the local resources of the development unit. The Emergy density (ED) reflecting resource gradient available for economic utilization (Su et al., 2009, 2010).

Organization demonstrates the composition and diversity of ecosystems (Yan et al., 2016), which refers to the interconnection relationship between the components, and which is proportional to the number and interaction of components of the ecosystem. The more complicated the organization structure, the much healthier the ecosystem. The present research chooses Non-renewable emergy ratio (NER), Emergy per capita (EPC), and Emergy exchange rate (EER) to present the composition and diversity of ecosystems.

The ability of the ecosystem to resist stress, that is, when the external stress has been eliminated that the ability of the ecosystems to return to their original state, is termed as resilience (Yan et al., 2016). The resilience of ecosystem depends on its own condition in a certain region and period, without changes of the composition of ecosystem, and correspondingly the type of the complex ecosystem and ecosystem elasticity also remained stable without change. Due to some emergy-based index, such as renewable resource emergy ratio and environmental load rate (ELR), are relevant (Liu et al., 2009a), we choose Waste produce ratio (WPR) and Environmental load rate (ELR) to express the resilience factor (Liu et al., 2009a; Su et al., 2009). It is true that critical ecosystem services at different scales are different, but for the regional ecosystem health assessment, the indicators should be selected based on regional characteristics and spatial scales to effectively represent the fundamental ecosystem services (Yan et al., 2016). The focus of urban ecosystem health is sustainable ecosystem services that supports the human with material, goods and services (Liu et al., 2009a). Therefore, the maintenance of urban ecosystem services determines the possible supply of the urban ecosystem resource for urban residents, which can be expressed by the Emdollaratio (EDR) (Liu et al., 2009b), Emergy self-sufficiency rate (ESR) and the Emergy Sustainability Index (ESI). 
Based on the built framework, the assessment method of ecosystem health in the study area is divided into three steps.

(1) Calculating the emergy flow and related emergy indicator. The calculation equation is organized on the basis of emergy concept in order to aggregate input flows according to their characteristics and to convert traditional units (such as $\mathrm{J}, \mathrm{g}, \$$ ) into emergy units (sej) (Yu et al., 2016). The equation (1) represents the solar emergy of all input flows as showed:

$$
U=\sum\left(T_{r_{i}} E_{i}\right) i=1,2,3, \cdots, n
$$

Here, $\mathrm{U}$ is the total emergy of input flows, with a unit of $\operatorname{sej}$ (Yu et al., 2016); $E_{i}$ is $i$ th input flow of material or energy; and Tri is the unit emergy value (UEV) of the $i$ th input flow.

(2) Standardizing the emergy index, and calculating the weight of index on the basis of information entropy. Because these indicators that vary greatly with different evaluating objectives have more significant impaction on the final evaluation results. Therefore, information entropy is applied to calculated the weights of each index of the EHI (Su et al., 2009). In this paper, $M=\left\{m_{r}\right\}$ is indicator set, usually with different types, here $M_{1}$ is positive and $M_{2}$ is negative (ratio of electricity emergy used, Waste produce ratio and emdollaratio are negative, the other are positive).

$$
\begin{gathered}
\mathrm{W}_{r}=\frac{\left(1+\frac{1}{\ln p} \sum_{k=1}^{p} \frac{q_{k r}}{q_{r}} \ln \frac{q_{k r}}{q_{r}}\right)}{\left(n+\frac{1}{\ln p} \sum_{r=1}^{n} \sum_{k=1}^{p} \frac{q_{k r}}{q_{r}} \ln \frac{q_{k r}}{q_{r}}\right)} \quad\left(\sum_{r=1}^{n} \mathrm{~W}_{r}=1,0 \leq \mathrm{W}_{r} \leq 1\right) \\
\mathrm{q}_{r}=\sum_{k=1}^{p} \mathrm{q}_{k r} \\
\mathrm{q}_{k r}= \begin{cases}\frac{I_{k r}}{I_{k r}^{*}}, & I_{k r}^{*}=\max \left(I_{k r}\right), m_{r} \in M_{1} \\
\frac{I_{k r}^{*}}{I_{k r}}, & I_{k r}^{*}=\min \left(I_{k r}\right), m_{r} \in M_{2}\end{cases}
\end{gathered}
$$

Here $W_{r}$ is the weight of the index $m_{r}$, and $q_{r}$ is the integrated value of the indicator $m_{r}$, and $q_{k r}$ is the standardized value which derived from the raw data of indicator $m_{r}$. 
(3) The formula for calculating urban ecosystem health index (EHI):

$$
E H I=\sum\left(W_{i} m_{i}\right) i=1,2,3, \cdots, n
$$

$E H I$ presents ecosystem health score, $m_{i}$ is the $i$ th standardized emergy indicator, $W_{i}$ is weight of $i$ th ecosystem emergy indicator, and $n$ is the number of ecosystems emergy indicators.

Taiyuan City, the capital of China's Shanxi Province with the 3 million population, is universally acknowledged as one of the most polluted cities in the world (Mestl et al., 2005). Located at the eastern margin of the Loess Plateau, in the central part of Shanxi, and in the north part of Jinzhong Basin (Zhang et al., 2010a), between the east longitudes $111^{\circ} 30^{\prime}-113^{\circ} 09^{\prime}$, and north latitudes $37^{\circ} 27^{\prime}-38^{\circ} 25^{\prime}$ (see Figure 2).

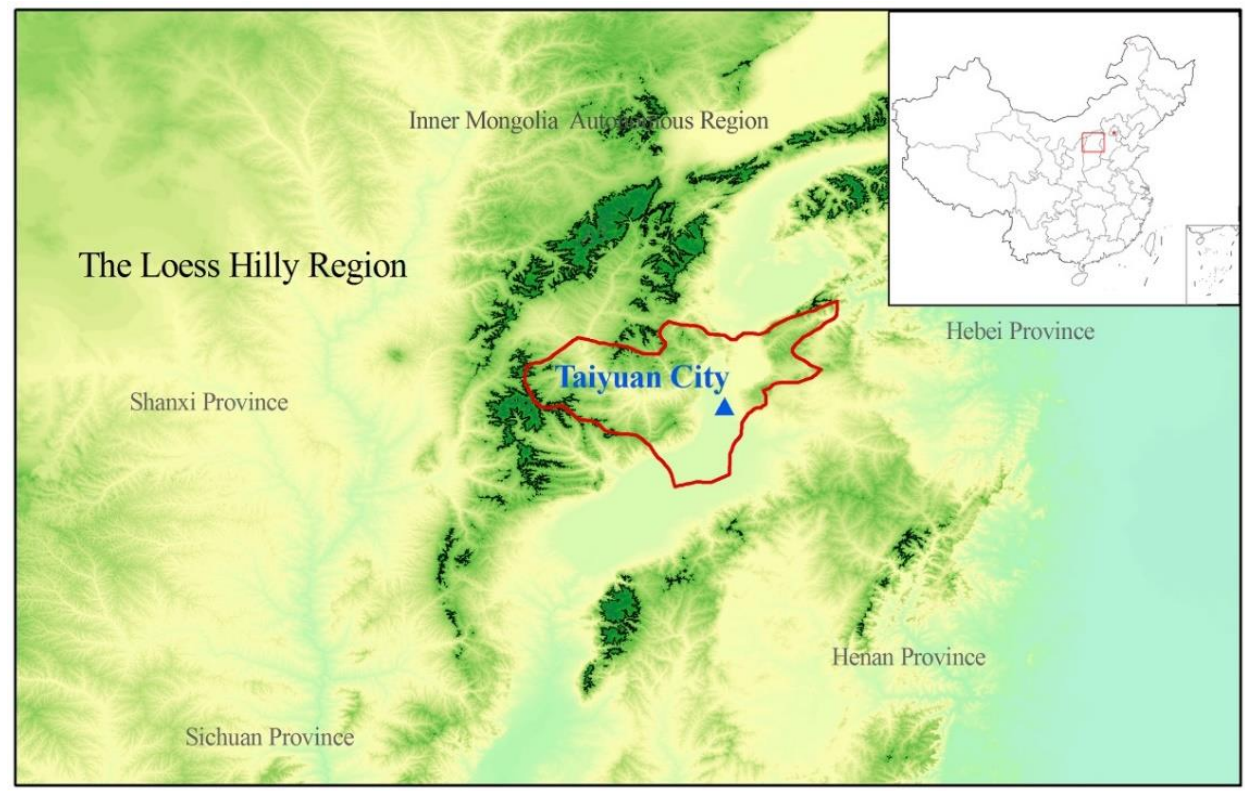

Figure 2. Location of the study area

As the important energy and heavy chemical industry bases of China, Taiyuan's economy high relies on the heavy industry, which contributed to more than $75 \%$ of its GDP. The urbanization rate in Taiyuan has increased from $54.38 \%$ to $84.70 \%$ from 2001 to 2017, far higher than the national average of 58.52\%. Rapid urban sprawl has promoted the social and economic development, but meanwhile have caused a series of environmental issues, such as the shortage of water resources, serious environmental pollution, fragile ecological environment and so on. Owing to special topography, which surrounded by hills and mountains, thus results in periods of countercurrent and stagnant air masses in the winter, accordingly strengthening the concentration of air 
pollutants (Zhang et al., 2010a). In summary, Taiyuan was chosen as a suitable case study for evaluating the ecosystem health.

The data used in this paper are derived from Shanxi Statistical Yearbook 2002-2018, Taiyuan Statistical Yearbook 2002-2018, and the achievement of the 30-years "Reform and Opening-up" of Shanxi (Shanxi Province Statistical Bureau, 1983-2015, 2009). And, unit emergy value (UEV) of materials and energy flows were drawled on the experience of related references (Jiang et al., 2009; Su et al., 2010; Pan et al., 2019).

\section{Results}

The dynamic emergy flow information on Taiyuan urban ecosystem during the 17-years period was calculated using the equation (1). Using information entropy, in light of the expression of indicator system (Table 1) and the equations (2) (5), we can calculate the emergy efficiency index and the weight of each indexes, with weight we can finally obtain the Vigor, Organization, Resilience, Ecosystem service and EHI. Using this method, we obtained the urban ecosystem health evaluation table of Taiyuan (Table 2).

Table 2. The urban ecosystem health evaluation table of Taiyuan (2001-2017)

\begin{tabular}{|c|c|c|c|c|c|c|c|c|c|c|c|c|c|}
\hline & \multicolumn{4}{|c|}{ Vigor } & \multicolumn{3}{|c|}{ Organization } & \multicolumn{2}{|c|}{ Resilience } & \multicolumn{3}{|c|}{ Ecosystem service } & \multirow{2}{*}{ EHI } \\
\hline & YR & ED & $\mathbf{E E}$ & IR & ER & EPC & ER & LR & WPR & EDR & ESR & ESI & \\
\hline 20 & & & & & 0.602 & $9.44 \mathrm{E}+15$ & 320 & 555 & 26 & $4.71 \mathrm{E}+12$ & 822 & 1.226 & c \\
\hline 2002 & 4.366 & $1.75 \mathrm{E}+11$ & 132 & 212 & 0.577 & $1.06 \mathrm{E}+16$ & 0.340 & 3.023 & 0.023 & $4.79 \mathrm{E}+12$ & 0.825 & 1.444 & 0.344 \\
\hline 200 & 4.780 & 1 & 130 & 208 & 0.558 & $8 E+16$ & 0.312 & 699 & 028 & $\mathrm{E}+12$ & 0.828 & 1.771 & 0.348 \\
\hline 2004 & 4.350 & $1.79 \mathrm{E}+11$ & 143 & 231 & 0.554 & $1.08 \mathrm{E}+16$ & 0.336 & 2.868 & 0.024 & $3.23 \mathrm{E}+12$ & 0.812 & 1.517 & 0.369 \\
\hline 2005 & 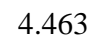 & 1 & 150 & 244 & 0.540 & $1.10 \mathrm{E}+16$ & 0.320 & 2.798 & 0.022 & $2.82 \mathrm{E}+12$ & 0.804 & 1.595 & 0.388 \\
\hline 2006 & 5.042 & $1.92 \mathrm{E}+11$ & 194 & 0.309 & 0.513 & $1.15 \mathrm{E}+16$ & 0.251 & 2.987 & 0.019 & $2.61 \mathrm{E}+12$ & 0.764 & 1.688 & 0.414 \\
\hline 2007 & 4.784 & $2.07 \mathrm{E}+11$ & 203 & 0.330 & 0.473 & $1.23 \mathrm{E}+16$ & 0.273 & 2.590 & 0.017 & $2.28 \mathrm{E}+12$ & 0.752 & 1.847 & 0.445 \\
\hline 2008 & 251 & $1.89 \mathrm{E}+11$ & 210 & 388 & 0.519 & $1.12 \mathrm{E}+16$ & 0.284 & 3.946 & 0.010 & $1.71 \mathrm{E}+12$ & 0.721 & 1.077 & 0.564 \\
\hline 2009 & 5.434 & +11 & 0.173 & 0.289 & 0.483 & $1.14 \mathrm{E}+16$ & 0.242 & 2.413 & 0.006 & $1.81 \mathrm{E}+12$ & 0.776 & 2.252 & 0.689 \\
\hline 2010 & 4.090 & $1.93 \mathrm{E}+11$ & 211 & 0.406 & 0.505 & $9.47 \mathrm{E}+15$ & 0.296 & 3.853 & 0.006 & $1.50 \mathrm{E}+12$ & 0.711 & 1.061 & 0.717 \\
\hline 2011 & 4 & ער & 233 & 0 & 0 & 1.04 & 0 & 3.315 & 0 & 12 & 0. & 1.2 & 0 . \\
\hline 2012 & 4. & $2.06 \mathrm{E}+11$ & 212 & 422 & 0.474 & 9.96 & 0.279 & 3.3 & 0.005 & 1.2 & 0.703 & 1.296 & 0.77 \\
\hline 2013 & 4.325 & $1.94 \mathrm{E}+11$ & 218 & 0.472 & 0.429 & $9.33 E+15$ & 0.282 & 2.989 & 0.006 & $1.11 \mathrm{E}+12$ & 0.680 & 1.447 & 0.753 \\
\hline 2014 & 4.191 & $1.92 \mathrm{E}+11$ & 0.225 & 0.509 & 0.434 & $9.18 \mathrm{E}+15$ & 0.285 & 3.365 & 0.007 & $1.04 \mathrm{E}+12$ & 0.663 & 1.246 & 0.755 \\
\hline 2015 & 3.470 & $1.89 \mathrm{E}+11$ & 0.241 & 0.518 & 0.438 & $9.03 \mathrm{E}+15$ & 0.354 & 3.530 & 0.006 & $9.39 \mathrm{E}+11$ & 0.659 & 0.983 & 0.801 \\
\hline 2016 & 4.018 & $1.95 \mathrm{E}+11$ & 0.238 & 0.446 & 0.426 & $9.25 \mathrm{E}+15$ & 0.317 & 2.769 & 0.005 & $8.96 \mathrm{E}+11$ & 0.691 & 1.451 & 0.920 \\
\hline 2017 & 4.071 & $1.94 \mathrm{E}+11$ & 0.256 & 0.436 & 0.429 & $9.14 \mathrm{E}+15$ & 0.313 & 2.740 & 0.005 & $7.93 \mathrm{E}+11$ & 0.696 & 1.486 & 0.938 \\
\hline Weights & 0.011 & 0.006 & 0.063 & 0.104 & 0.014 & 0.010 & 0.011 & 0.022 & 0.388 & 0.312 & 0.007 & 0.052 & -- \\
\hline
\end{tabular}


The vigor of Taiyuan City changed little, first slowly climbed up and began to decline in recent years, and its trend line like an elongated $S$ curve (Fig. 3). Among the vigor's indicates, the environmental investment ratio (EIR) accounted for the largest contribution, with a trend trajectory similar to that of vigor changes during the period 2001-2017. During 2001-2009, although EIS increased slowly, the value was always less than 0.3 , probably because the economic system is mainly dependent on local coal resource, more coal is obtained from the environment free of charge than other competitors. However, too low the rate of emergy investment will not be conducive to attracting extra-territorial funds, which in turn will affect the development of local resources. From 2010 to 2015, this ratio become large fast, that means inputs are need to pay, prices are rising, and the system is more competitive than past. But in recent years, the index has also declined, possibly due to the government optimizing industrial structure, and the dependence on the resources has not been as serious as past. For example, the industrial added value of the traditional heavy industries accounts for more than $80 \%$ of total industrial added value in 2001 , but this proportion has decreased to $39.3 \%$ in 2017.

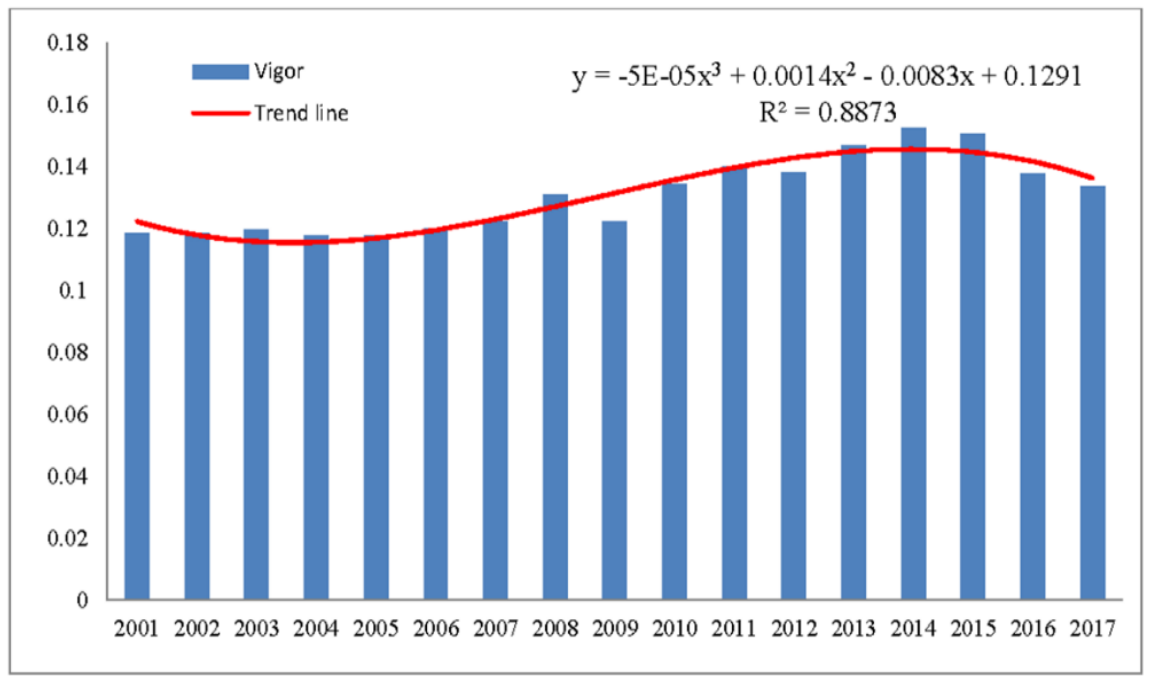

Figure 3. The vigor and its trend of Taiyuan urban ecosystem

According to Figure 4, we can find that the organization of Taiyuan has fluctuating declined during the 2001-2017 period. The trend line obeys polynomial regression, the equation is $\mathrm{y}=2 \mathrm{E}-05 \mathrm{x} 2-0.0007 \mathrm{x}+0.034\left(\mathrm{R}^{2}=0.8406\right)$, which reflects the trend line fit the organization well. The contribution of non-renewable emergy ratio (NER), emergy exchange rate (EER) and emergy per capita (EPC) to organization is almost the same level, which is $0.014,0.010$ and 0.011 , respectively. But in the recent two years, emergy exchange rate (EER) has slightly picked up. 
The resilience of Taiyuan urban ecosystem fluctuates greatly during the past 17-year period, but overall express rise trend (Fig. 5). Here, waste produce ratio (WPR) and Environmental load rate (ELR) were chosen to express the resilience factor. The contribution of waste produce ratio (WPR) and Environmental load rate (ELR)to resilience is 0.388 and 0.022 , respectively. Obviously, the continuous reduction of industrial waste emissions leads to ecosystem resilience improving.

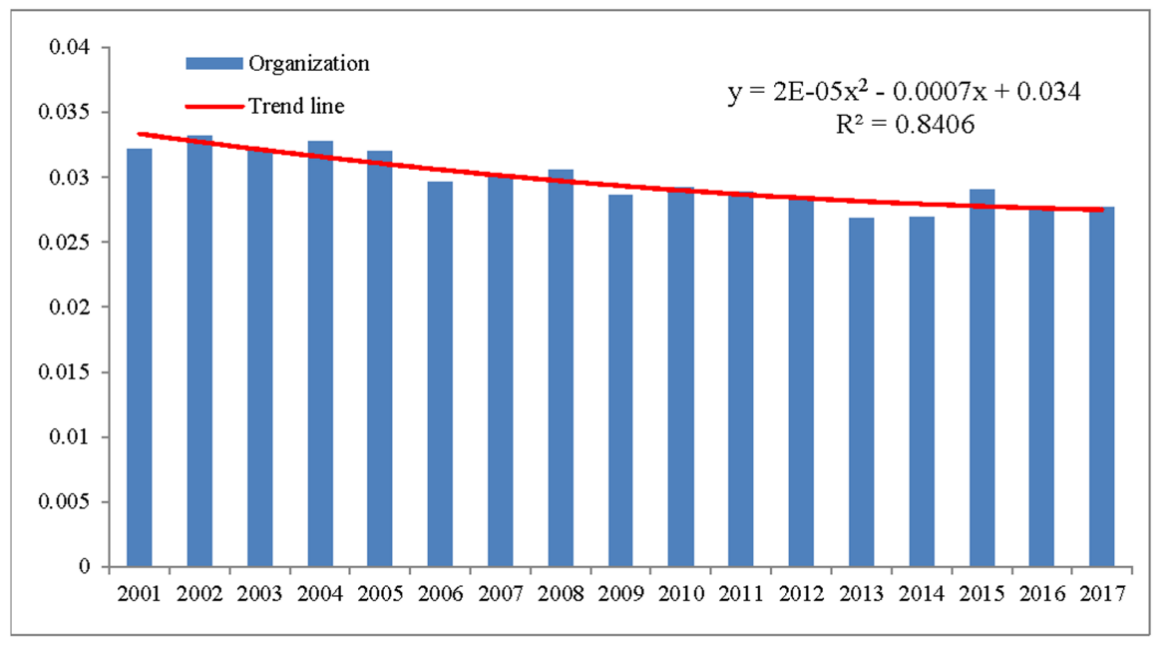

Figure 4. The organization and its trend of Taiyuan urban ecosystem

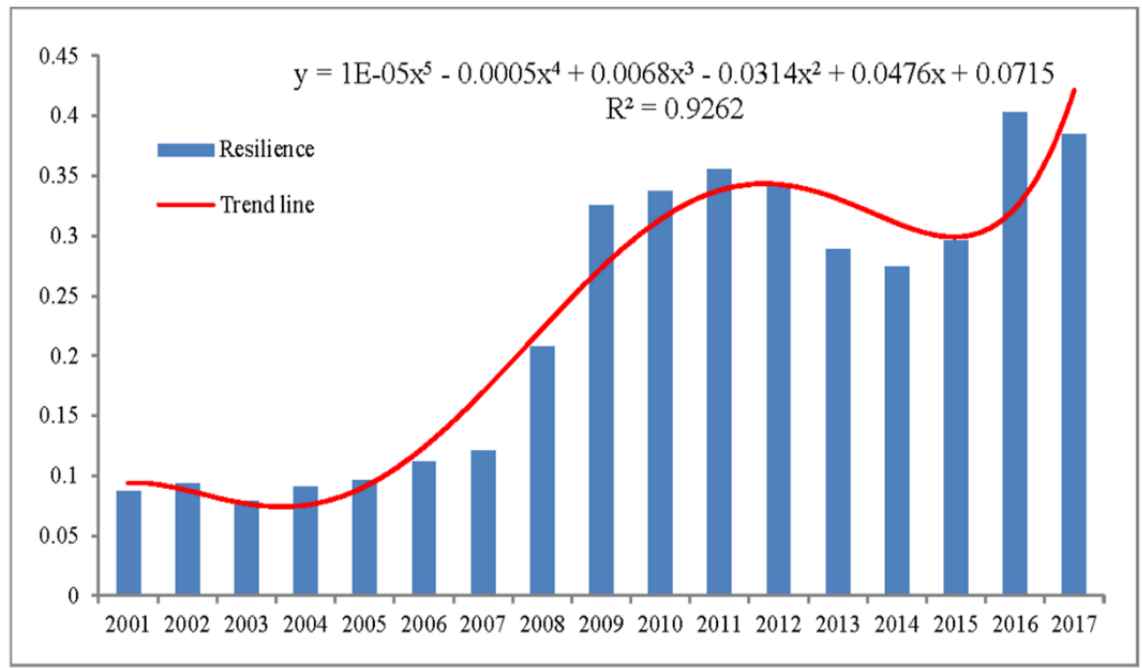

Figure 5. The resilience and its trend of Taiyuan urban ecosystem

Figure 6 shows that the urban ecosystem service of Taiyuan was exponential growth during the past 17-years period. The trend line obeys exponential regression, the equation is $\mathrm{y}=0.0899 \mathrm{e}^{0.088 \mathrm{x}}\left(R^{2}=0.9921\right)$, which reflects the trend line better fit the ecosystem service. The contribution of emdollaratio (EDR), emergy self-sufficiency 
rate (ESR) and emergy sustainability index (ESI) to ecosystem service is $0.312,0.007$ and 0.052 , respectively. To a great extent, the ecosystem service keeps climbing result from continuous decline of emdollaratio (EDR). In General, this rate is higher in the less developed regions, because natural resources are basis for its economic development and GDP growth (Yu et al., 2016), and most of the environmental resources are used free of charge. On the contrary, this ratio become lower means that the local economy developed because of rapid currency repayments, a large GDP base and the huge import of resources.

As showed in Figure 7, the trend of ecological health index and resilience of Taiyuan is very similar during the 2011-2017 period, but it is a little smoother. From the previous analysis, we know that this is mainly due to the resilience and ecological service capacity of Taiyuan urban ecosystem improved over the past 17 years.

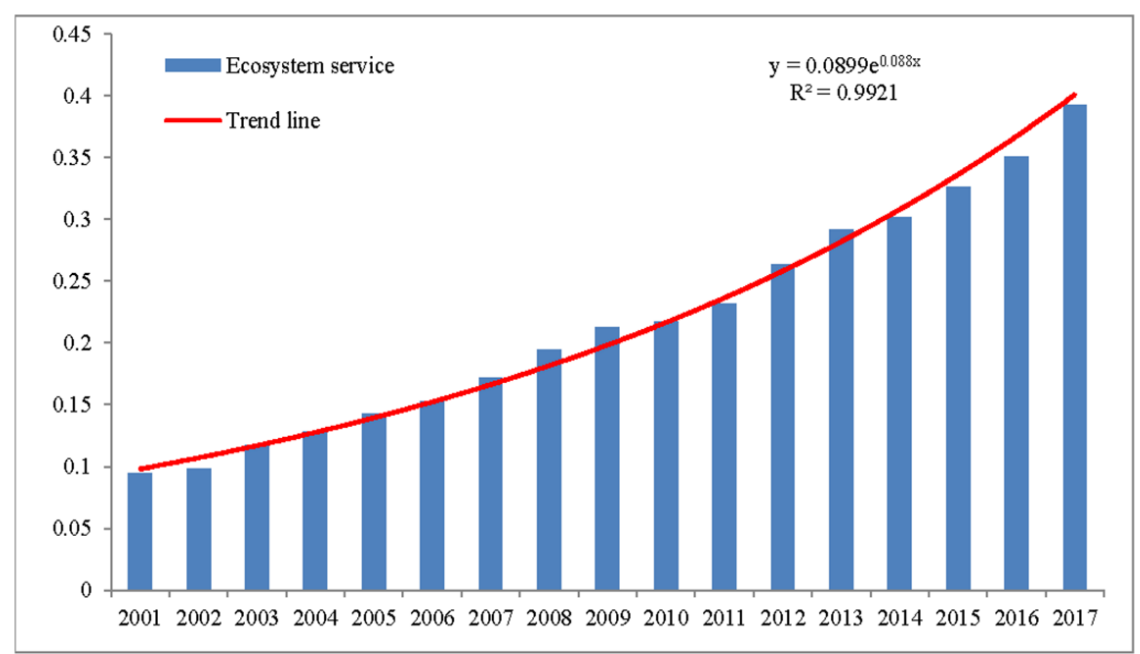

Figure 6. The urban eco-system service and its trend of Taiyuan

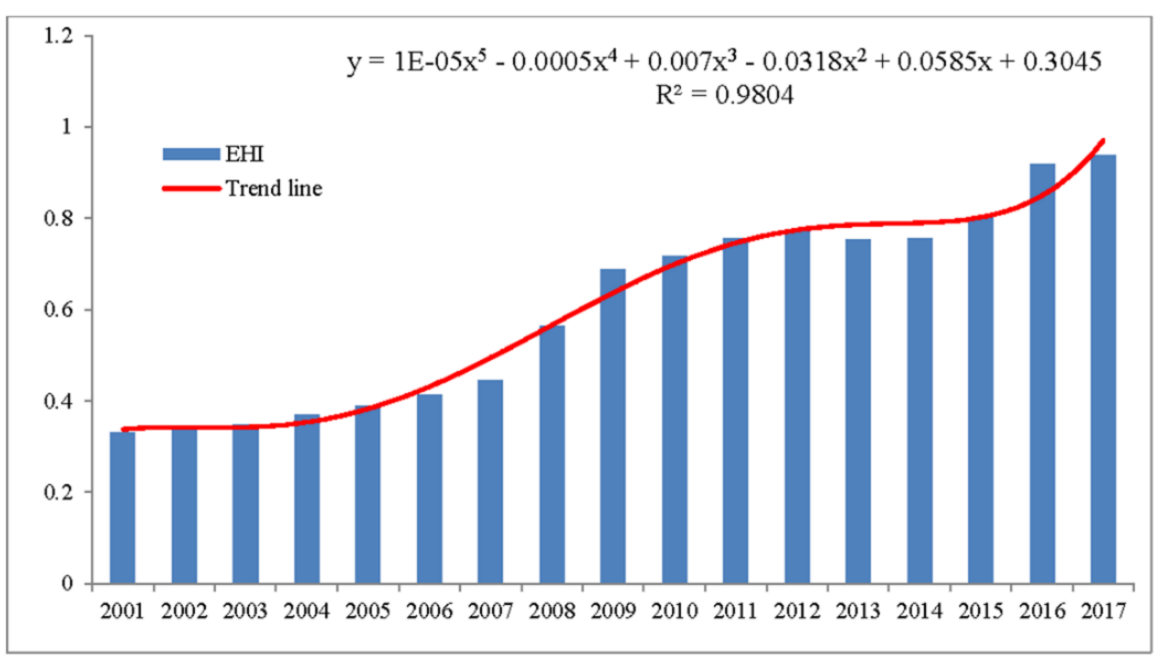

Figure 7. The EHI and its trend of Taiyuan urban ecosystem 
However, the vigor of Taiyuan urban ecosystem changed little, and even more cautiously since that there are still a lot of problems with the organizational structure. From Figure 8, we can also find that correlation coefficient of the ecological health index and were significant positive except for organization. Mostly because the organization of Taiyuan has fluctuating declined during the 17-years period.

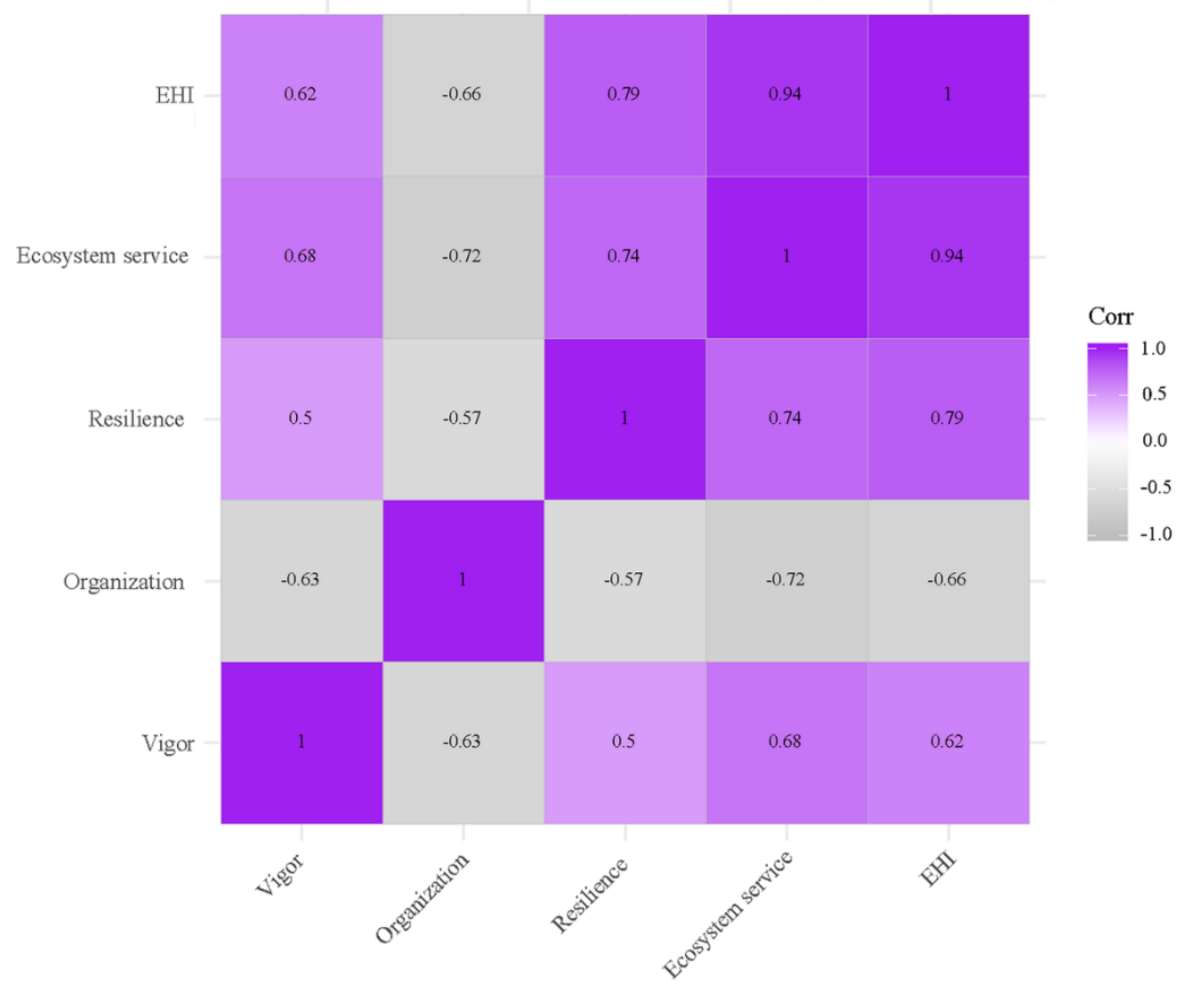

Figure 8. The correlation coefficient of EHI and VORS4. Discussion

\section{Discussion}

Recently, the relationship between economic growth and environmental performance is worth studying. As Silvio affirmed, cities are the engine of economic development and human wellbeing, however, their dynamics need to be supported by the convergence of a large number of material and energy resources (Viglia et al, 2018). Due to the contradiction between urban economic expansion and environmental protection becomes more and more serious, it is worth investigating the relationship between economic growth and environmental performance (Liu et al., 2009). Basically, the framework definition and application of metrics and models capable of accounting for natural capital value are much needed (Vassallo, 2017). It is necessary to formulate methods and indicators of ecosystem health and apply them to typical coal regional ecosystems (Jiang et al., 2009). This paper tries to construct a framework of assessment model and choose relevant index based on emergy, finally, combining information 
entropy method to evaluate the urban ecosystem health status from the perspective of the energy and materials metabolism. Nevertheless, there are still many problems that need to be studied in depth. What are the most key factors affecting the health of urban ecosystems, whether there is a causal relationship between them, whether they are short-term or long-term impaction, and so on.

As the provincial capital of Shanxi, Taiyuan's development is also a microcosm of Shanxi. Shanxi Province's coal yield accounts for $1 / 4$ of the total coal production in the whole country, whilst coke production accounts for $2 / 5$ (Guo et al., 2018). The energy intensity of Shanxi province is the highest all over the whole country, 2.4 times compared to the national average in 2006 (Tang et al., 2014). Although air pollution has improved since the early 1990s, the air pollution in the city is still very serious compared to other cities in the country. It is possible because the energy structure of Shanxi Province is mainly dependent on coal for a long time. That's also why the organization of Taiyuan has fluctuating declined. In order to reduce the coal consumption, Taiyuan municipal government intends to improve the current energy structure (Guo et al., 2018), optimize industrial structure, and the dependence on the resources has not been as serious as past. For example, Taiyuan municipal government invested 1.5 billion Yuan (180 million USD) to implement its cleaner production program for the purpose of improving the environmental condition, and in 1999 Taiyuan became China's first cleaner production pilot city (Mestl et al., 2005). According to relevant government reports, 12 industrial pollution sources were closed in 2005, and a total of 121 were shut down by 2012 (Tang et al., 2014). But considering the structure of the coal industry lasting almost 100 years, there is still a long way to go. It is necessary to find clean renewable resources to Offset the consumption of coal resources. The empower that is derived from solar, geothermal and tidal sources drives the productive processes, and make it possible to come true (Brown et al., 2016). Under such circumstances, government should take strong actions to reduce coal consumption and related emissions. In particular, the local government should play a leading role in promoting technological innovation among enterprises through carefully designed policies to improve product sustainability, and to regulate public behavior (such as green public transport travel, garbage classification, purchase of energy-saving products, etc.), thereby achieving a 'win-win' environment and economy.

\section{Conclusions}

This study applies emergy synthesis and information entropy to assess the urban ecosystem health of Taiyuan during the period 2001-2017, to provide suggestions for local government formulating the policy and regulation. Result shows that the ecological health of Taiyuan has improved during the 2011-2017 period, mainly due to the resilience and ecological service capacity of Taiyuan urban ecosystem improved over the past 17 years. The continuous reduction of industrial waste emissions leads to 
ecosystem resilience improving. However, we should be cautious since that there are still a lot of problems with the organizational structure. And in order to reduce the dependence on the resources, Taiyuan government still needs to improve the current energy structure and optimize industrial structure. In the future study, how to take into account the space-time dimension, compare and analyze the resource-based cities' ecological health in China and predict the trend of ecological health development will be the core work of the next step. At the same time, how to improve the accuracy of its measurement, and then identify the key factors that affect the health of urban ecosystem, and provide a clearer basis for urban development, is also the important research direction.

Acknowledgments. We thank Rong Zhou for her great assistance in this study. We would also like to thank the Science and Technology Basic Resources Survey Project of China (2017FY101304), Major R\&D Project of Chinese Academy of Sciences (ZDRW-ZS-2016-6-5), National Natural Science Foundation of China (41701062,41471116,41701142), Shanxi Scholarship Council of China (2016-078), Shanxi Normal University Natural Science Foundation (ZR1714), and the Youth Innovation Promotion Association CAS (2016181). We are also grateful to the anonymous reviewers and all the editors in the process of revision.

\section{REFERENCES}

[1] Bagliani, M., Galli, A., Niccolucci, V., Marchettini, N. (2008): Ecological footprint analysis applied to a sub-national area: the case of the Province of Siena (Italy). - J. Environ. Manag 86(2): 354-364.

[2] Barles, S. (2009): Urban Metabolism of Paris and Its Region. - Journal of Industrial Ecology 13(6): 898-913.

[3] Brown, M. T., Ulgiati, S. (2016): Emergy assessment of global renewable sources. Ecological modelling 339: 148-156.

[4] Browne, D., Bernadette, O. R., Moles, R. (2011): Material flow accounting in an irish city-region 1992-2002. - Journal of Cleaner Production 19(9-10): 967-976.

[5] Chen, W., Geng, Y., Dong, H., Tian, X., Zhong, S., Wu, Q., Xu, Y., Zhang, Q., Li, S. (2018): An emergy accounting based regional sustainability evaluation: A case of Qinghai in China. - Ecological indicators 88: 152-160.

[6] Dong, X., Zhang, Y., Cui, W., Xun, B., Yu, B., Ulgiati, S., Zhang, X. (2011): Emergy-based adjustment of the agricultural structure in a low-carbon economy in Manas County of China. - Energies 4(9): 1428-1442.

[7] Gommans, L., Dobbelsteen, V. D. A. (2007): Synergy between exergy and regional planning. - WIT Transactions on Ecology and the Environment 105: 103-112.

[8] Graymore, M. L., Sipe, N. G., Rickson, R. E. (2008): Regional sustainability: how useful are current tools of sustainability assessment at the regional scale? - Ecol. Econ 67(3): $362-372$. 
[9] Guo, X., Zhang, Z., Zhao, R., Wang, G., Xi, J. (2018): Association between coal consumption and urbanization in a coal-based region: a multivariate path analysis. Environmental Science and Pollution Research 25(1): 533-540.

[10] Huang, S. L. (2004): Energy basis for urban ecological economic system. - Chans Bookstore 147-151. (in Chinese).

[11] Huang, S. L., Lee, C. L., Chen, C. W. (2006): Socioeconomic metabolism in Taiwan: emergy synthesis versus material flow analysis. - Resour. Conserv. Recycl 48(2): 166-196.

[12] Huang, S. L., Kao, W. C., Lee, C. L. (2007): Energetic mechanisms and development of an urban landscape system. - Ecological Modelling 201(3-4): 495-506.

[13] Jiang, M. M., Chen, B., Zhou, J. B., Yang, Z. F., Ji, X., Zhang, L. X., Chen, G. Q. (2009): An ecological evaluation of Beijing ecosystem based on emergy indices. Communications in Nonlinear Science and Numerical Simulation 14(5): 2482-2494.

[14] Kovanda, J., Weinzettel, J., Hak, T. (2009): Analysis of regional material flows: the case of the Czech Republic. - Resour. Conserv. Recycl 53(5): 243-254.

[15] Lei, K., Zhou, S., Hu, D., Yu, Y. (2010): Ecological energy accounting for the gambling sector: A case study in Macao. - Ecological Complexity 7(2): 149-155.

[16] Liu, G. Y., Yang, Z. F., Chen, B., Ulgiati, S. (2009a): Emergy-based urban health evaluation and development pattern analysis. - Ecological Modelling 220(18): 2291-2301.

[17] Liu, G. Y., Yang, Z. F., Chen, B., Zhang, Y., Zhang, L. X., Zhao, Y. W., Jiang, M. M. (2009b): Emergy-based urban ecosystem health assessment: A case study of Baotou, China. - Communications in Nonlinear Science and Numerical Simulation 14(3): 972-981.

[18] Liu, X., Guo, P., Guo, S. (2019): Assessing the eco-efficiency of a circular economy system in China's coal mining areas: Emergy and data envelopment analysis. - J. Clean. Prod 206: 1101-1109.

[19] Mestl, H. S., Aunan, K., Fang, J., Seip, H. M., Skjelvik, J. M., Vennemo, H. (2005): Cleaner production as climate investment-integrated assessment in Taiyuan City, China.J. Clean. Prod 13(1): 57-70.

[20] Odum, E. P. (1979): Perturbation theory and the subsidy-stress gradient. - BioScience 29(6): 349-352.

[21] Pan, H. Y., Zhuang, M. F., Geng, Y., Wu, F., Dong, H. J. (2019): Emergy-based ecological footprint analysis for a mega-city: The dynamic changes of Shanghai. - Journal of Cleaner Production 210: 552-562.

[22] Perkins, A., Hamnett, S., Pullen, S., Zito, R., Trebilcock, D. (2009): Transport, housingand urban form: The life cycle energy consumption and emissions of city centre apartments compared with suburban dwellings. - Urban Policy and Research 27(4): 377-396.

[23] Ricardo, E. V. A., Mathias, G., Robert, H., Norma, A. O. G., Rabindranarth, R. L. (2013): An emergy analysis for urban environmental sustainability assessment, the Island of Montreal, Canada. - Landscape and Urban Planning 118: 18-28.

[24] Shanxi Statistical Bureau. (2001-2018): Shanxi Statistical Yearbook. - China Statistics Press: Beijing. (in Chinese). 
[25] Shanxi Statistical Bureau. (2009): Province Bureau of statistics of Shanxi. Exhibition of the achievement on 30-year "Reform and Opening-up" of Shanxi. - China Statistics Press: Beijing. (in Chinese).

[26] Su, M. R., Yang, Z. F., Chen, B., Ulgiati, S. (2009): Urban ecosystem health assessment based on emergy and set pair analysis-A comparative study of typical Chinese cities. Ecological modelling 220(18): 2341-2348.

[27] Su, M., Yang, Z., Chen, B. (2010): Relative urban ecosystem health assessment: A method integrating comprehensive evaluation and detailed analysis. - Eco. health 7(4): 459-472.

[28] Taiyuan Statistical Bureau. (2002-2018): Taiyuan Statistical Yearbook (2001-2018). China Statistics Press: Beijing. (in Chinese).

[29] Tang, D. L., Wang, C. C., Nie, J. S., Chen, R. J., Niu, Q., Kan, H. D., Chen, B. H., Perera, F., Taiyuan, C. D. C. (2014): Health benefits of improving air quality in Taiyuan, China. Environment international 73: 235-242.

[30] Viglia, S., Civitillo, D. F., Cacciapuoti, G., Ulgiati, S. (2018): Indicators of environmental loading and sustainability of urban systems. An emergy-based environmental footprint. Ecological indicators 94: 82-99.

[31] Wang, X., Liu, G., Coscieme, L., Giannetti, B. F., Hao, Y., Zhang, Y., Brown, M. T. (2019): Study on the emergy-based thermodynamic geography of the Jing-Jin-Ji region: Combined multivariate statistical data with DMSP-OLS nighttime lights data. - Ecological Modelling 397: 1-15.

[32] Xiao, R., Liu, Y., Fei, X., Yu, W., Zhang, Z., Meng, Q. (2019): Ecosystem health assessment: A comprehensive and detailed analysis of the case study in coastal metropolitan region, eastern China. - Ecological Indicators 98: 363-376.

[33] Xu, F. L. (1997): Exergy \& structural exergy as ecological indicators for the development state of Lake Chao ecosystems. - Ecol. Model 99(1): 41-49.

[34] Xu, X., Xu, X., Chen, Q., Che, Y. (2015): The impact on regional "resource curse" by coal resource tax reform in China-A dynamic CGE appraisal. - Resources Policy 45: 277-289.

[35] Yan, Y., Zhao, C., Wang, C., Shan, P., Zhang, Y., Wu, G. (2016): Ecosystem health assessment of the Liao River Basin upstream region based on ecosystem services. - Acta Ecologica Sinica 36(4): 294-300.

[36] Yu, X. M., Geng, Y., Dong, H. B., Fujita, T., Liu, Z. (2016): Emergy-based sustainability assessment on natural resource utilization in 30 Chinese provinces. - J. Clean. Prod 133: 18-27.

[37] Zhang, D., Aunan, K., Martin, S. H., Larssen, S., Liu, J., Zhang, D. (2010a): The assessment of health damage caused by air pollution and its implication for policy making in Taiyuan, Shanxi, China. - Energy Policy 38(1): 491-502.

[38] Zhang, Y., Singh, S., Bakshi, B. R. (2010b): Accounting for ecosystem services in life cycle assessment, Part I: A critical review. - Environmental Science and Technology 44(7): 2232-2242.

[39] Zhang, Y., Yang, Z., Liu, G., Yu, X. (2011): Emergy analysis of the urban metabolismof Beijing. - Ecological Modelling 222(14): 2377-2384. 
[40] Zhang, Z., Xue, B., Pang, J., Chen, X. (2016): The decoupling of resource consumption and environmental impact from economic growth in china: Spatial pattern and temporal trend. - Sustainability 8(3): 222.

[41] Zhou, X., Imura, H. (2011): How does consumer behavior influence regional ecological footprints? An empirical analysis for Chinese regions based on the multi-region inputeoutput model. - Ecol. Econ 71: 171-179. 